\title{
NUMERICAL CALCULATION ON SHORELINE CONSERVATION IN MAJURO ATOLL, THE MARSHALL ISLANDS
}

\author{
Daisaku Sato ${ }^{1}$ and Hiromune Yokoki ${ }^{1}$
}

\begin{abstract}
Development of a numerical model for future estimation of morphological changes in Majuro atoll were carried out, and, at the same time, examination of beach nourishment for sustainable island conservation plan was examined by the developed model. Identified erosion and accretion area from calculated shoreline indicated that the northern tip of Laura and some areas in LongIsland had severe erosion until 100 years later as well as large accretion in northern part of the atoll. Three beach nourishment scenarios using eroded sediments, which were accreted in deep lagoon in northern part of atoll, were examined and they decreased $30 \%$ of accumulative erosion volume compared with the non-conservation result. This result shows that the beach nourishment is an effective option to sustainable island conservation plan in Majuro atoll.
\end{abstract}

Keywords: Majuro atoll; island conservation; numerical simulation

\section{INTRODUCTION}

Atoll islands distribute all over the world. There are 500 atolls in the world and about 400 of those are locating in the pacific region (Kayanne et al., 2005). Lagoon formed by ring-shaped reefs has several tens meters depth, which is quite shallow compared with the depth on outer ocean whose depth is several thousands meters. Lagoon is partly connected to outer ocean with artificial and natural passages generally. Water depth on the ring-shaped reef is several meters and it expose in low tide. Islands are formed on the ring-shaped reefs. These islands are low-lying and flat with maximum altitude of several meters (Yamano et al., 2005). Foraminifers and the other organisms such as corals and shells are major sediments to construct the island, because atoll islands have no river. (Yamano et al., 2005: Yokoki et al., 2005).

Coastal erosion is significant problem in atoll islands because the atoll islands are generally small and narrow shapes. Atoll islands have two different coasts that are lagoon-side and ocean-side coast. Coral rubbles generally construct ocean-side coast and it is stable except tropical cyclone season. In the lagoon-side coast, fine sands form coast, where the active sediments transportation due to lagoonal waves causes coastal morphological changes. For that reason, the coastal erosion in atoll islands is focused on lagoon-side coast mainly.

In addition, atoll islands are highly vulnerable to environmental changes and extreme events (Leatherman, 1997; Nurse et al., 2001; Yamano et al., 2005). In particular, the sea-level rise is one of the most notable impacts of global climate change on atoll coasts in the near future (Letherman, 1997). The sea-level rise causes various impacts on atoll islands. Coastal erosion and its acceleration due to the projected sea-level rise are significant problems on atoll islands (Mimura et al, 2007). The countermeasure against the sea-level rise is called adaptation, which is indispensable for the sustainable islands conservation.

Morphological changes in atoll islands are caused by natural and artificial factors. In the natural factors, waves and currents are main external forces, which transport the sediments. However, the interaction between morphological changes in the islands and the waves that transport sediment is not understood enough (Yokoki et al., 2005; Kench and Brander, 2006). On the morphological changes of individual atoll, Sato and Yokoki (2008) carried out a numerical simulation of wave field and sediment transport in Majuro atoll, the Marshall Islands without the interaction, which was based on the simple coastal change process: sediment supply, transport, and accretion or erosion. Then, Sato and Yokoki (2009) conducted a numerical simulation on morphological changes in Majuro atoll and showed that the calculated morphological changes agreed with the realistic coastal change volume, which was calculated by using observed beach profiles.

In order to discuss sustainable and effective island conservation, the future morphological changes including influence of the sea-level rise should be identified. Studies on numerical simulation of morphological changes in atoll islands are not enough and it is not clear what kind of countermeasure is desirable for sustainable conservation plan. Then, this study was focused on Majuro atoll, Republic of the Marshall Islands and has three major objectives: to develop the numerical model, which enables

\footnotetext{
${ }^{1}$ Department of Urban and Civil Engineering, Ibaraki University, 4-12-1 Nakanarusawa, Hitachi, Ibaraki, 316-8511, Japan
} 
to estimate future morphological changes in Majuro atoll, to estimate future morphology of Majuro atoll in order to identify detail of erosion and accretion, and to examine beach nourishment scenarios as sustainable conservation plans in Majuro atoll.

\section{Majuro Atoll}

Majuro atoll is the capital of Republic of the Marshall Islands and locates in Pacific (7.1065806N, 171.37532E) (Fig. 1). The width from east to west is about $40 \mathrm{~km}$ and the width from north to south is about 20km. Darrit-Uliga-Delap(DUD) area is located in the eastern side of the Majuro atoll and the capital facilities concentrate there. In the western side of the atoll, Laura islet is located, which is widest islet in Majuro atoll and is about $1.2 \mathrm{~km}$ wide. These two major areas are connected by the very narrow island called Long Island area. In the northern atoll, there are many small islets with or without human settlements and vegetation. In the center of the northern rim, a large artificial passage had been constructed for cargo ships and fishing boats. DUD area and eastern half of Long Island have very narrow reef-flat on the lagoonal coast. On the other hand, the reef-flat on the lagoonal coast of the western half of Long Island and Laura islet is wide. The lagoonal reef-flat in front of Laura islet is double-formed reefs.

The sediments of atoll islands are dominantly foraminifers and the other organisms such as corals (Yamano et al., 2005). Similarly, in Majuro atoll, the sediments are mainly composed of the foraminifers such as Baculogypsina and Calcarina, whose ratio are about 80\% (Yasukouchi, 2007). Two different materials construct the coastal sediments in Majuro atoll that are sands and coral gravels. Sands in Majuro atoll consist of foraminifers and corals. They are very fine and mainly exist on the lagoonal coast. DUD area located in the eastern atoll has no sandy beach on the lagoon-side coast. In these areas, artificial seawalls are constructed along the lagoonal coast. Long Island area is separated into two major areas that are eastern-side and western-side. The eastern area has artificial coast along the lagoon, and the western area has relatively rich sandy beaches. The largest island in western end of Majuro atoll, Laura islet, has wider sandy beaches than other areas. In particular, the northern tip of Laura islet has the widest and largest sandy beach. Oppositely, coral gravels are main materials on the ocean-side coast and the size of those is more than tens of centimeters. These sediments would be carried at extreme events such as tropical cyclones and stormy waves. In Funafuti atoll of Tuvalu, the tropical cyclone Bebe stroked in 1972 and the large amount of coral gravels and rubbles accreted on the ocean-side reef-flat (Maragos et al., 1973; Mergner, 1985). After that, these accreted sediments transported by high waves toward the islands and finally they combined together with the main island (Baines and McLean, 1976). Thus, the extreme events have high potential for transport sediments and it cause large morphological changes. However, extreme events strike to atoll islands once in a decade

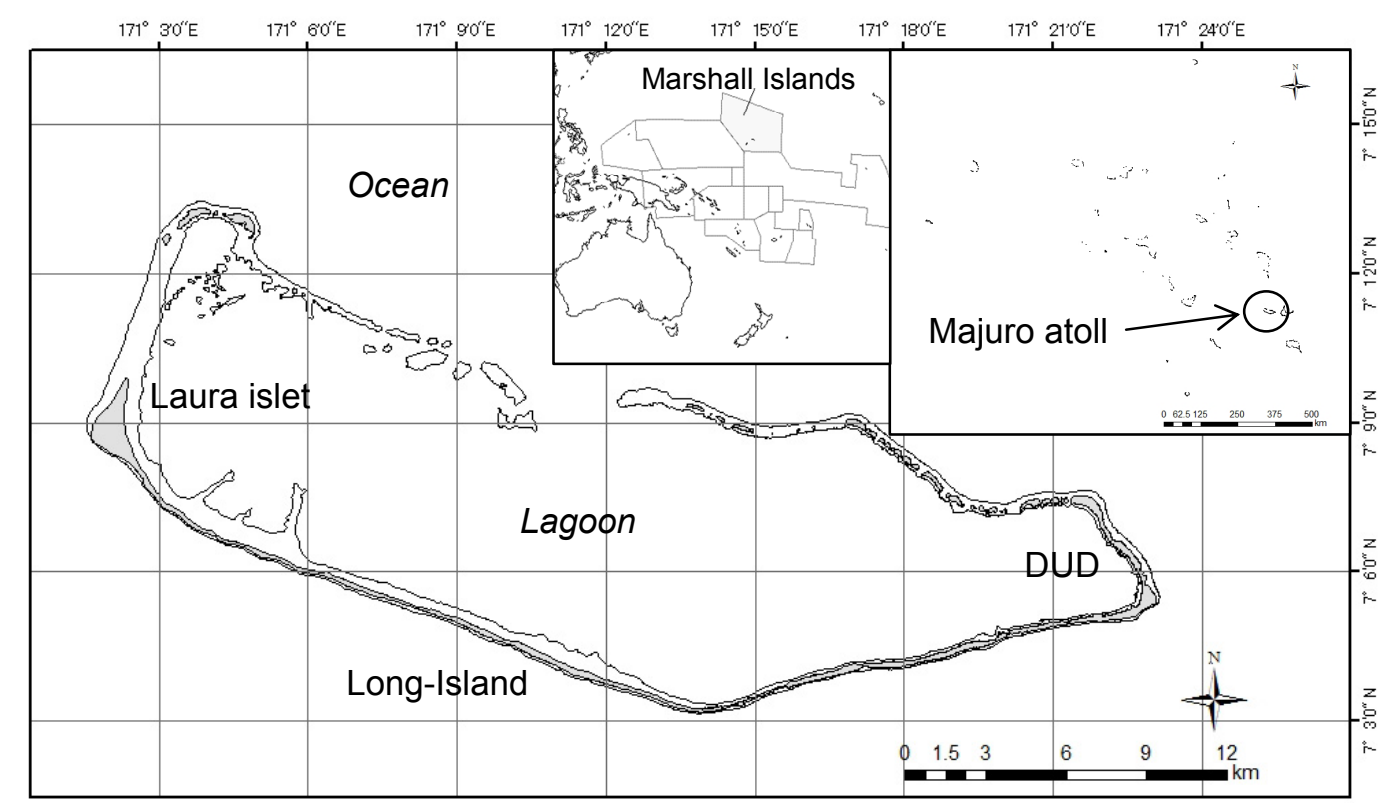

Figure 1. Location of Majuro atoll, Republic of the Marshall Islands 

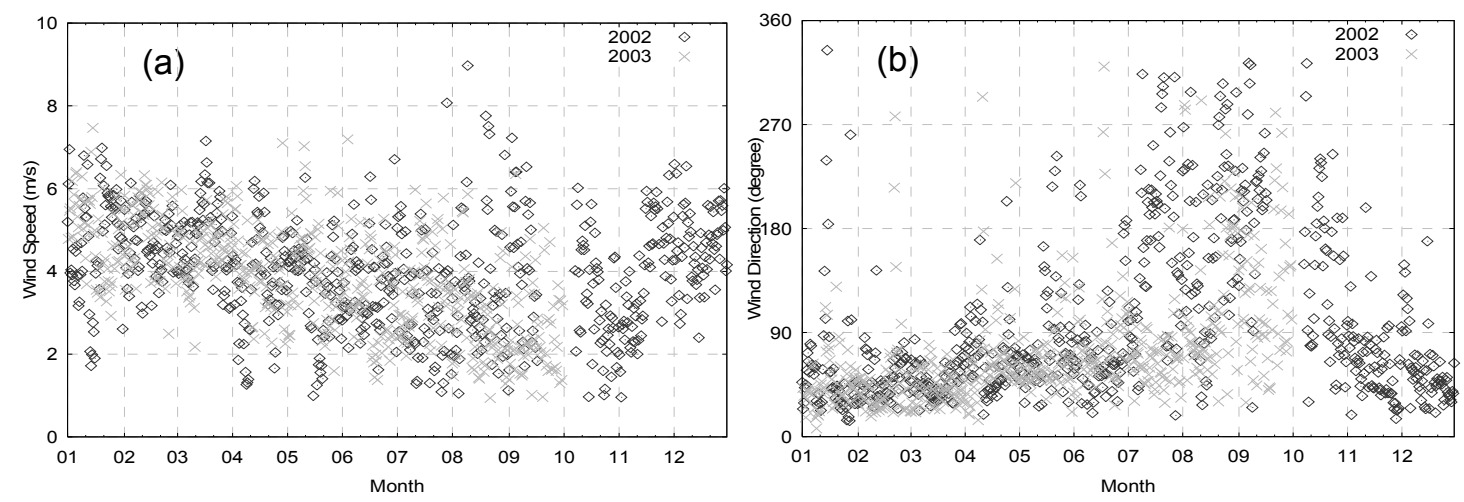

Figure 2. (a) Wind speed from 2002-January and 2003-Octover. (b) Wind direction in the same period. The original data were observed hourly at the Majuro Weather Station located in Uliga districts. Both figures indicated the daily average calculated from the original data. In the Figure 2(b), the degree 0 and 90 indicate that the wind come from east and north respectively

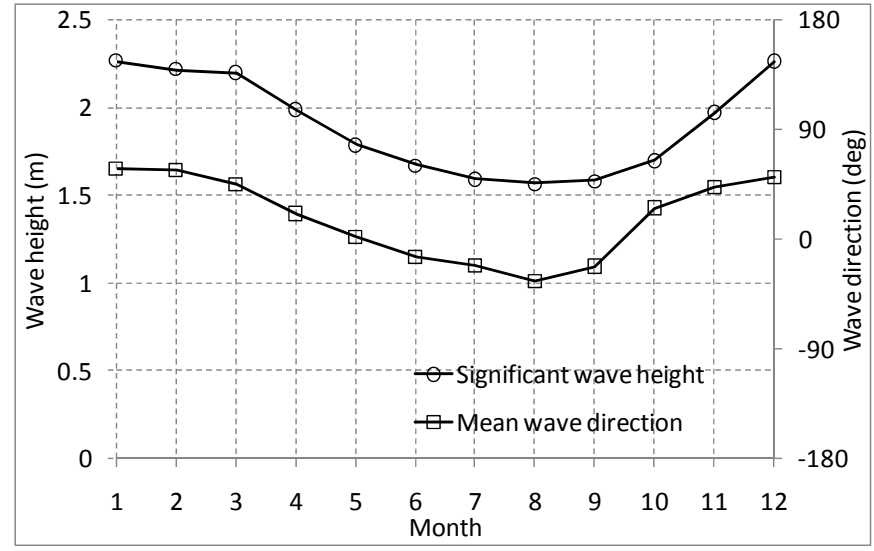

Figure 3. Monthly averages of the significant wave height and mean wave direction of the ocean swell in Majuro. The data observed every six hours from 1990 and 1999 offered by the European Center for Middle Weather Forecast (ECMWF). The $\mathbf{0}$ and $\mathbf{9 0}$ degree of wave direction indicate that the waves come from north and east respectively

or more. Therefore, the extreme events are very rare phenomena in the atoll islands. In the view of the daily and seasonal scale, the transportation of the fine sand in lagoonal coast is main factor on morphological change.

Figure 2 shows the daily wind condition from January 2002 to October 2003 at Majuro atoll. The original hourly data were observed at the Majuro weather station located in Uliga district. In the wind directions shown in the Fig. 2(b), the degree 0 and 90 indicate that the wind comes from the east and north, respectively. From November to June, the trade wind blows mainly from northeast with larger wind speed. The direction of trade wind distributes mainly between 0 and 90 degree. In the trade wind season, the winds blow from almost same direction continuously with low wind speed. From July to October, the wind speed decrease and the wind blows from various directions. These characteristics of winds influence the both lagoonal and oceanic wave situations. Although the wind condition was observed on the island, the island is very low and there are no obstacles. Then, the characteristic of winds can be considered as on both the island and the sea.

Majuro atoll has the two different seas that are the lagoon and the ocean. Figure 3 shows the monthly-averaged significant wave heights and mean wave directions of the oceanic swells around Majuro atoll. The original data were offered every six hours from 1990 to 1999, which were reanalyzed by the European Center for Middle Weather Forecast (ECMWF). The 0 and 90 degree of the wave direction indicate the waves come from north and east, respectively. From December to March, the significant wave heights are larger than those in other months are. From April to November, the swell becomes weaker and the minimum wave height appears in August. As this trend is similar to the change of the trade wind, it is indicated that the oceanic swell is highly influenced by the wind. 
Annual or seasonal waves in the lagoon are not observed in Majuro atoll. Yokoki et al. (2005) focused on the wind waves in the lagoon and the diffracted waves coming through the northern passage and calculated by a numerical method. They calculated the wind waves using SMB method and the diffracted waves with a Helmholtz equation method, respectively and the comparison of the each longshore wave energy flux indicated that the longshore wave energy flux of the wind waves corresponded to the coastal changes in Majuro atoll.

There are some researches on morphological changes in Majuro atoll. The Pacific Islands Applied Geoscience Commission (SOPAC) measured the beach profiles at Laura islet in 1997 and 1998 (SOPAC, 1997; 1998). We followed the same survey lines to measure beach profiles in 2006, 2007 , and 2008, and revealed the sediment volume changes during the past 10 years at each survey line by comparing between SOPAC's profiles and ours (Sato and Yokoki, 2008). They indicated that the northern tip area of Laura islet had severe erosion in the past 10 years, and its lagoon-side coasts have both erosion and accretion. Similarly, Yokoki et al. (2005) indicated the significant erosion in the northern tip of Laura islet, by comparing with the aerial photo pictured in 1944 and IKONOS image pictured in 2000 .

In a qualitative view, Xue (2001) reported that, according to local residents and coco trees' position, the tip of Laura islet had undergone significant recent erosion, and it was caused by lack of the longshore sediment transport from east to west. In addition, Fujita et al. (2008) revealed that the lagoonal coast in Rita and Uliga located on the western side of Majuro atoll, which is the upstream of the sediment transport according to Xue (2001), has no sediment production by foraminifera such as Calcalina and Amphistegina. Sato et al. (2006) simulated the longshore sediment transport including the sediment production by foraminifers and pointed out the sediment production volume was extremely smaller than the volume of the longshore sediment transport.

Sato and Yokoki (2008) constructed the morphological change model of Majuro atoll based on the simple process include the sediment supply, longshore sediment transport, and accretion or erosion. The calculated net longshore sediment transport during the past 10 years satisfactorily agreed with the realistic sediment volume change calculated by the beach profile differences between 1997 and 2007 at each survey line except for some points, where extremely high accretion and erosion potentials were calculated. Because the direction of longshore sediment transport was quite sensitive to the angle of shoreline to the incident wave direction, it was considered that the lack of interaction between waves and morphological change in the model caused such extremely peak of accretion or erosion. The past field investigation and numerical studies on Majuro atoll showed the validity of the concept of the morphological change based on the longshore sediment transport. However, the numerical model constructed by Sato and Yokoki (2008) lacked of the significant process that is the interaction between waves and morphological change. Accordingly, the calculated results of the sediment volume change showed unexpected large accretion and erosion potential in some calculation points. Then, Sato and Yokoki (2009) revised the simulation flow to obtain the results which agreed better with the measured morphological changes than the results by Sato and Yokoki(2008).

\section{Concept of numerical simulation}

Morphological changes in Majuro atoll were caused by various factors that are not only natural forces but also human impacts such as beach mining. In natural forces, the principal factors are different in the view of time scale and these complex forces transport sediments. It is difficult to simulate the morphological changes caused by such complex factors so that the simple process on morphological changes was assumed, which was based on the concept shown in Sato and Yokoki (2008). Sato and Yokoki (2008) focused on the difference of the external forces affecting to the characteristics of morphological changes in Majuro atoll (Fig. 4). Figure 4 indicates simple assumption on morphological changes, which include the two kinds of external forces in normal and extreme conditions. The normal condition includes oceanic swell, wind wave, and tidal current, which attack to atoll in daily and seasonally time scale. Fine and lightweight sands are transported under these conditions, which are mainly located on the lagoonal coasts.

Majuro atoll has experienced extreme weather conditions several times so far. The tropical cyclone attacked directly in November 1991 and November 1997 according to the best truck data from 1945 and 2008 offered by the Joint Typhoon Warning Center (JTWC). By 1945, it is reported that the severe damage caused by typhoon in 1905 and 1918 (Xue, 1997). These historical data show that the extreme events attacked to the Majuro atoll once in several decades. Transported materials in these extreme conditions are coral gravels with some tens centimeters or larger in the ocean-side coast mainly. 
Factors of the morphological changes

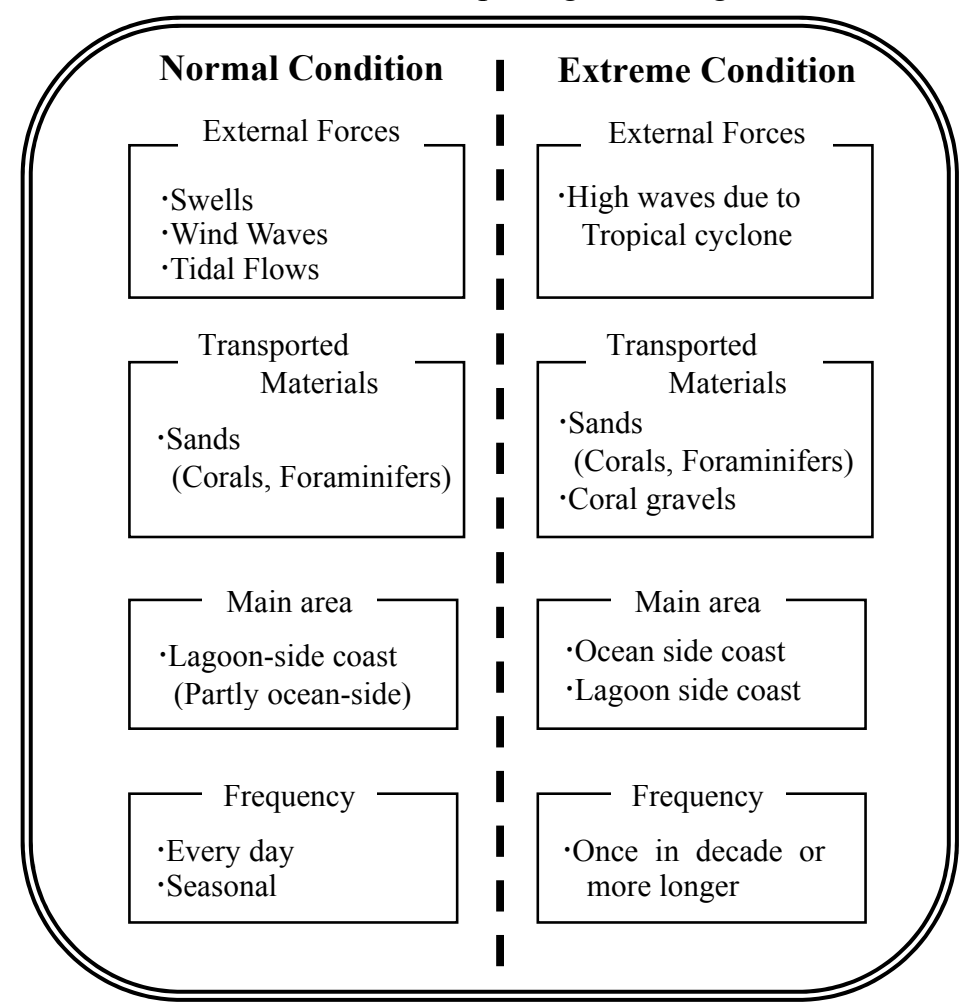

Figure 4. Simple assumption on the factors of morphological changes in Atoll islands (After Sato and Yokoki (2008)). Morphological changes were divided two conditions by the differences of external forces, transported materials, areas and frequency. The normal condition indicates that the wave height is under several meters. The extreme condition indicates extremely higher wave height than normal condition

As similar to Sato and Yokoki (2008), this study focused on the normal external forces condition that transports fine sands on the lagoon-side coast mainly. As more than $80 \%$ of the island's sediments are fine foraminifer sand (Yasukouchi, 2008), the sand movement on the lagoonal coast is important for understanding and estimating the island morphological changes. Xue (2001) also pointed out that the longshore sediment transport in the lagoon coast from east to west has high importance to form the Laura islet located in western part of the atoll, and it showed the existence of the longshore sand drift. Transportation of coral gravels in ocean-side coast, which caused by tropical cyclones is also important but it is quite rare in Majuro atoll.

Figure 5. shows the simulation flow that adapted in this study. In order to calculate long-term changes with effective processing time, simulation component was divided two steps that are the outerand inner-iteration part. The outer-iteration part included small iteration part and it calculated the wave field simulation that is the driving forces of the sediment transportation. Output variables from wave field simulation are significant wave height, mean wave direction, significant wave's period and length. The simulation was continued until 100 years later and the outer part was iterated once in decade. Increasing rate of sea-level at every ten years adopted the scenario offered by IPCC AR4 which the sea-level increased about $59 \mathrm{~cm}$ after 100 years. Inner iteration part included calculation of the longshore component of wave energy flux, the volume of longshore sediment transport and representative shoreline position. The volume of sediment supply from foraminifers, which was calculated based on Fujita et al (2008), was also considered in this part. This part was iterated once a year and it was continued for ten years using same wave field. After the inner-iteration part finished, the bathymetrical data was updated by the new shoreline position for next calculation of outer part. 


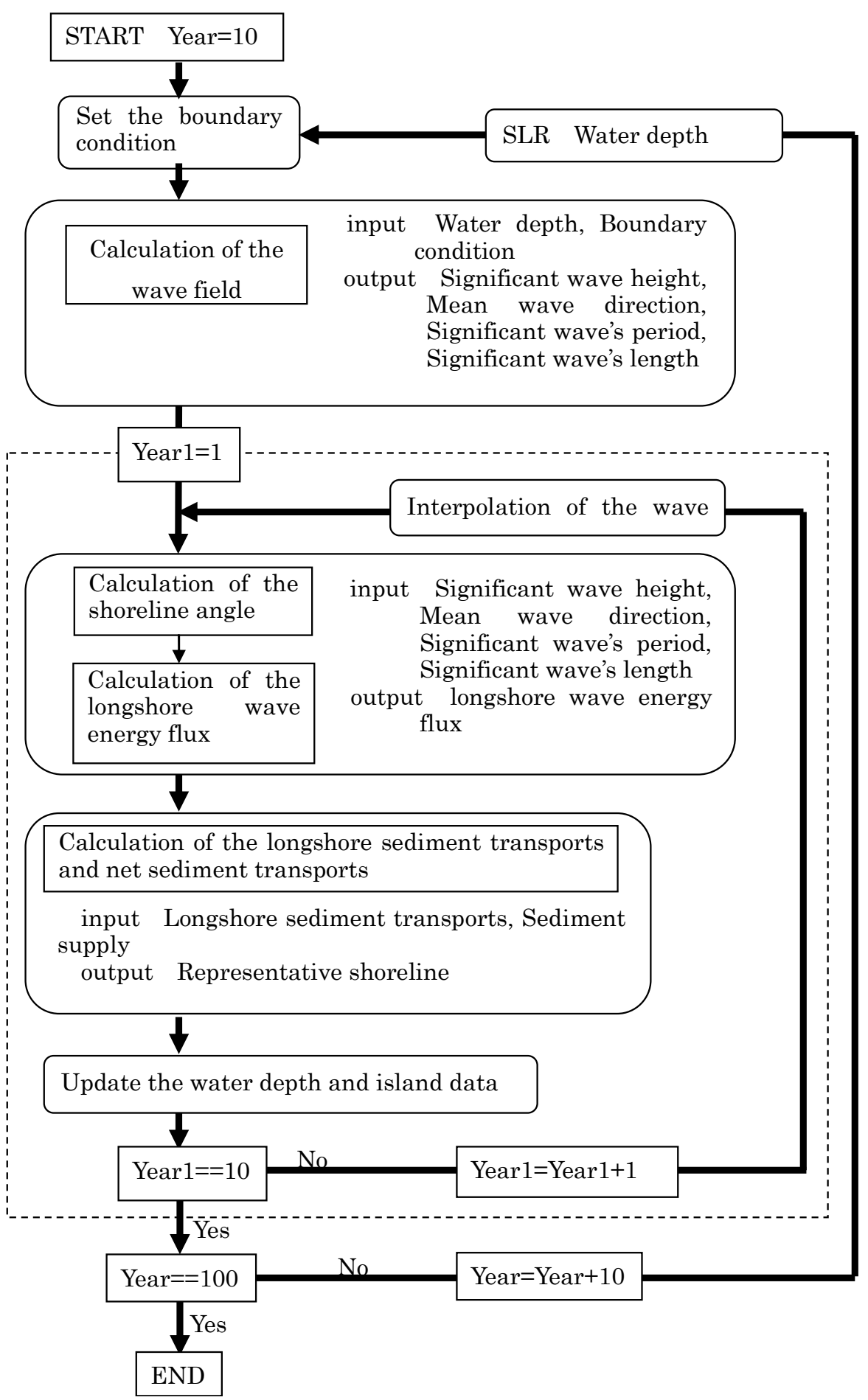

Figure 5. Simulation flow in this study

\section{Calculation method}

The simulation targeted wind waves and swells as the driving forces of sediment transport. We used the Simulating WAves Nearshore (SWAN) model to simulate the transformation of these waves. The model treats waves as a two-dimensional wave action density spectrum. The basic equation is shown in Eq. (1) (Booij et al., 1999):

$$
\frac{\partial}{\partial t} N+\frac{\partial}{\partial x} C_{x} N+\frac{\partial}{\partial y} C_{y} N+\frac{\partial}{\partial \sigma} C_{\sigma} N+\frac{\partial}{\partial \theta} C_{\theta} N=\frac{S}{\sigma}
$$




\begin{tabular}{|l|l|}
\hline \multicolumn{2}{|l|}{ Table 1. Incident wave and wind conditions } \\
\hline & Values \\
\hline Significant wave height $(\mathrm{m})$ & 1.9155 \\
\hline Mean wave direction(deg) & 239.4337 \\
\hline Significant wave's period(s) & 9.5932 \\
\hline Mean wind speed(m/s) & 5.1809 \\
\hline Mean wind direction(deg) & -81.8557 \\
\hline
\end{tabular}

\begin{tabular}{|c|c|c|c|c|}
\hline & $0-10$ years & $10-20$ years & $20-30$ years & $30-40$ years \\
\hline Increasing value $(\mathrm{m})$ & 0.000 & 0.042 & 0.038 & 0.048 \\
\hline & $40-50$ years & $50-60$ years & $60-70$ years & $70-80$ years \\
\hline Increasing value $(\mathrm{m})$ & 0.044 & 0.056 & 0.058 & 0.051 \\
\hline & $80-90$ years & $90-100$ years & \multirow{2}{*}{\multicolumn{2}{|c|}{$\begin{array}{l}\text { Based on the IPCC AR4 } \\
\text { Unit: } m\end{array}$}} \\
\hline Increasing value $(\mathrm{m})$ & 0.055 & 0.147 & & \\
\hline
\end{tabular}

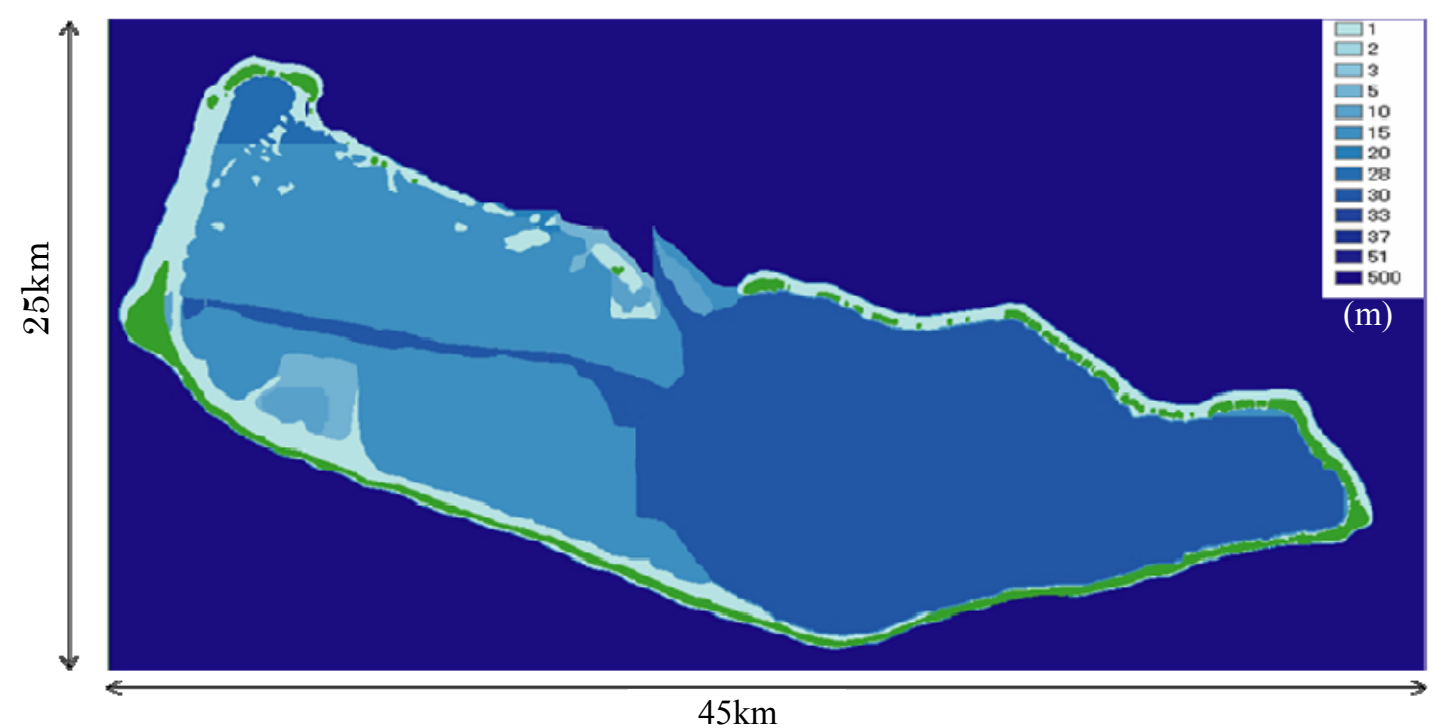

Figure 6. Calculation domain and water depth

where $t$ is the time, $x$ and $y$ is the horizontal direction, $\sigma$ is the angular frequency of wave, $\theta$ is the wave direction taken counterclockwise from the geographic east. $N$ is the wave action density; $C x, C y$ are the propagation velocities in the horizontal directions, respectively; $C \sigma$ is the propagation velocity in $\sigma$-space; and $C_{\theta}$ is the propagation velocity in $\theta$-space. $S$ in the right-hand side of the Eq. (1) is the source term in regards of energy density, representing the effects of wave generation, dissipation, and nonlinear wave-wave interactions.

For simulating of SWAN, the boundary condition of waves and winds adopted the annual-averaged data calculated using the collected data shown in Fig.2 and Fig.3 (Table 1). The increasing rate of sealevel was calculated by projected sea-level rise offered from IPCC AR4 (Table 2). Figure 6 . shows the calculation domain, which was approximately $45 \mathrm{~km}$ west-east and $25 \mathrm{~km}$ north-south and covers the entire Majuro atoll. We extracted the atoll's landforms and reef lines from the IKONOS image pictured in 2001. The calculation grid was rectangular and its size was set at approximately $32 \mathrm{~m}$. Water depth in the lagoon was digitized from the chart surveyed in 1954; we assumed a uniform $1 \mathrm{~m}$ water depth on the reef flat because of the lack of detailed data on the reef flat.

Longshore components of wave energy flux $P$ at each nearshore grid was calculated by the simulated nearshore significant wave height, mean wave direction, significant wave period, and significant wavelength, as shown in Eq. (2): 


$$
P=\frac{1}{8} \rho g H_{b}^{2} C_{g b} \sin \alpha \cos \alpha
$$

where $\rho$ is density of seawater, $H_{b}$ is significant wave height, $C_{g b}$ is group velocity calculated from the significant wave period and significant wavelength, and $\alpha$ is the angle of the mean wave direction to the shoreline. The total weight of longshore sediment transport was calculated from the longshore components of wave energy flux as in Eq. (3) (Komar and Inman, 1970):

$$
Q=\frac{K}{\left(\rho_{S}-\rho\right) g} P
$$

where $\rho_{s}$ is density of the sediment, and $Q$ is the volume of sediment transport. Then, 0.39 was applied to the value of $K$ as a general coefficient (CERC, 1984). After that, the net volume of the longshore sediment transport was calculated along the coastline from west DUD district to east Laura islet using the continuity equation of the longshore sediment transport as in Eq. (4):

$$
\frac{\partial Q_{v o l}}{\partial t}=\frac{\partial Q}{\partial \xi}+q
$$

where $Q_{v o l}$ is net volume of longshore sediment transport, $\xi$ is the alongshore coordinate. $q$ is sediment production volume in each month. Annual sediment production volume at each area indicated by Fujita et al., (2008) and we calculated annual-averaged production volume at each production area.

Sediment volume ratio at each mesh was calculated for describing the representative shoreline position. Calculation of the net volume of longshore sediment transport adopted the same grid system used in the wave field calculation. The size of the mesh was $32 \mathrm{~m}$ in $x$ - and $y$ direction. In $z$ direction, the island elevation was assumed as $2 \mathrm{~m}$ uniformly. As initial condition, the island meshes without shoreline were set to $100 \%$ of sediment volume ratio and those with shoreline were set to $50 \%$. In the meshes without island, the sediment volume ratio was set to $0 \%$. If the sediment volume ratio was calculated to be over $100 \%$, the new shoreline mesh was created in front of the old shoreline mesh and the old shoreline mesh became the island without shoreline. On the contrary, if the sediment ratio became $0 \%$, the island mesh changed to the water mesh with $1 \mathrm{~m}$ water depth as on the reef. Expansion of the shoreline mesh was limited by existence of the reef-flat.

\section{Estimated morphological changes in Majuro atoll}

Calculation of representative shoreline changes was carried out for whole of Majuro atoll. The results of the simulation in small areas indicated in Fig. 7 were discussed in this section respectively.

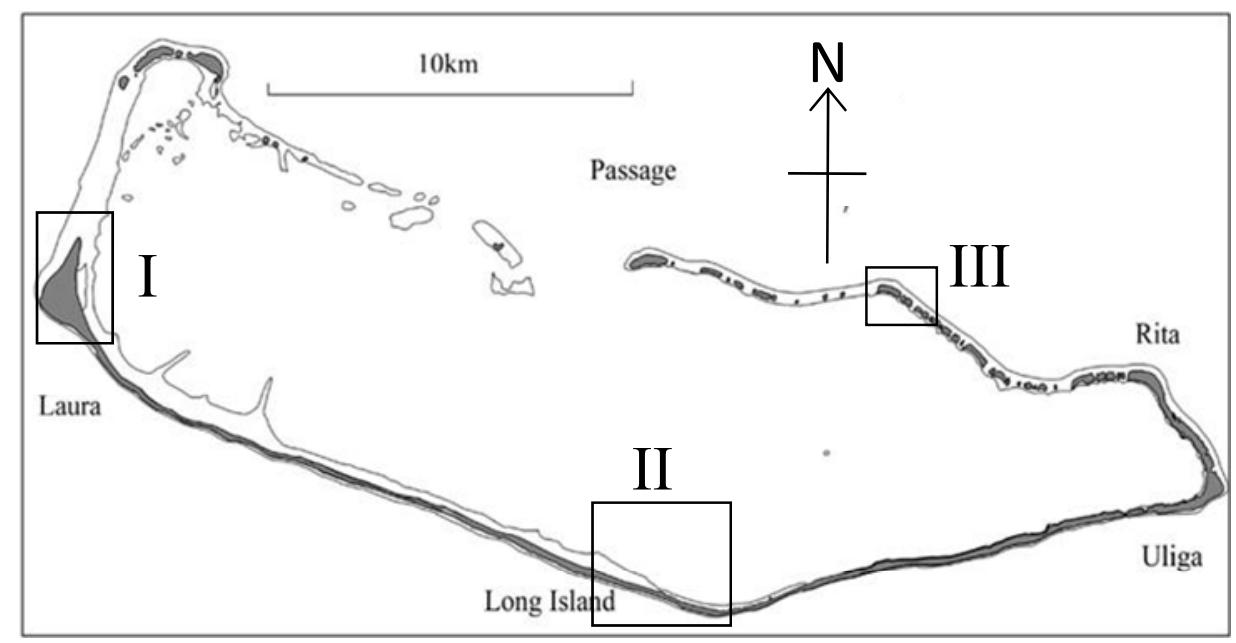

Figure 7. Focused area of estimated representative shoreline changes 


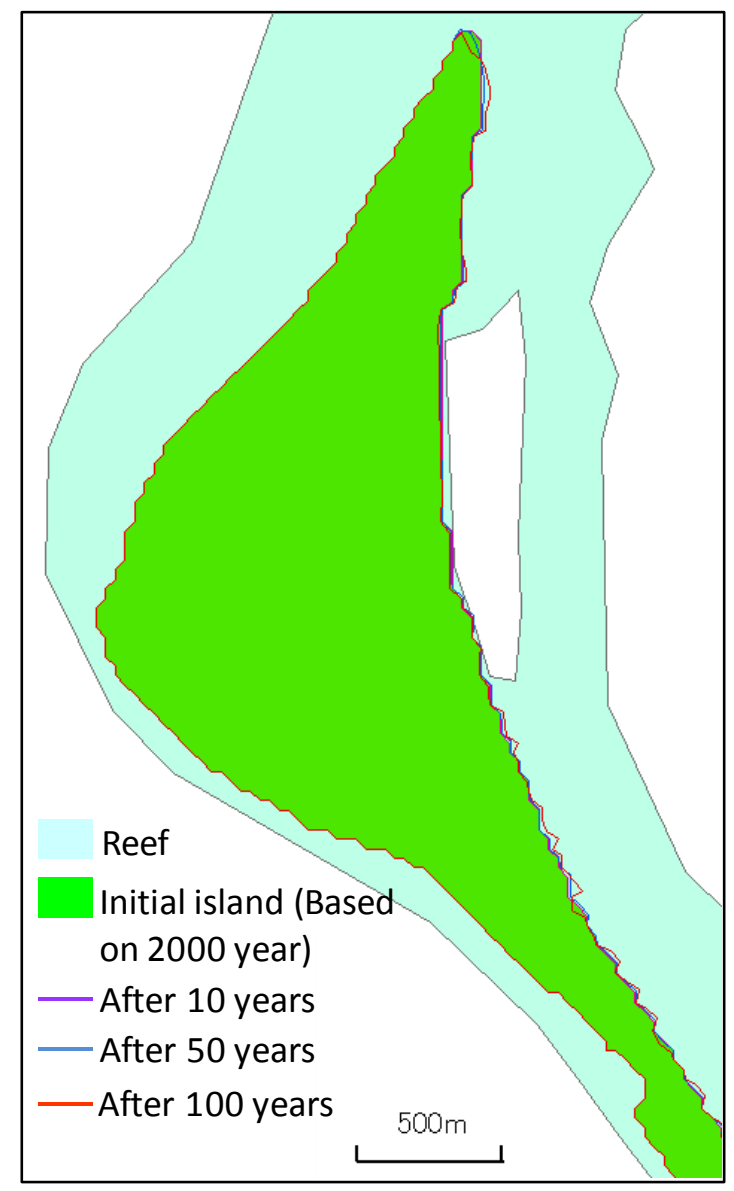

Figure 8. Calculated result of representative shoreline changes in Laura islet located in western part of the Majuro atoll

Area-I is Laura islet and Area-II is the middle of the LongIsland. Area-III shows small islet in northern atoll.

Figure 8 indicated the calculated results of representative shoreline position in Laura islet. The light-blue area shows the reef-flat and the green area shows the initial island shape, which was digitized from satellite image pictured in 2000. Lines of violet, blue and red indicate the calculated shoreline position after 10,50 and 100 years respectively. Figure 8 indicated that the northern tip of Laura islet has large erosion in anytime and this erosion accelerated between 50 and 100 years. It seems that the eroded sediment in the northern tip of Laura accreted nearby southern coast because the volume of eroded and accreted areas is almost same. Middle and southern part of Laura islet have shoreline changes slightly so that these coasts are stable under the projected sea-level rise and the estimated wave situation.

Figure 9 (a) shows the calculated results in middle part of LongIsland as shown Area-II in Fig. 7. This area faces to largest passage in northern atoll and island's width is very narrow. Compared with the eastern coast of this area, western coast has large changes both accretion and erosion. This area has very small production rate of sediments so that the island's volume in this area is not increase. In the largest eroded area, the shoreline retreated more than $100 \mathrm{~m}$ from initial position. It can be considered that the severe erosion connects to the damage of island infrastructures such as road because the width of island is very narrow. Figure 9 (b) shows the calculated results in small islet located northern part of the atoll, where is indicated in Fig. 7 as Area-III. In this area, there are many channels so that the waves enable to pass to lagoon through channels. The significant characteristic in this area is that the potential of sediment production of foraminifers is high (Fujita et al, 2008). From Fig. 9 (b), the large accretions in lagoon-side coast are identified. It seems that these accretion caused by characteristic of wave direction and high sediment production rate in this area. Focusing on the shoreline position after 100 years, the lagoon-ward accretion connects two separated islands. 
In this simulation, the expansion of island was controlled by existence of the reef edge. When net accreted volume was calculated beyond the reef edge due to large accretion, the volume was treated as 'outflow sediment volume', which dropped to the deeper lagoon and never returned to the longshore

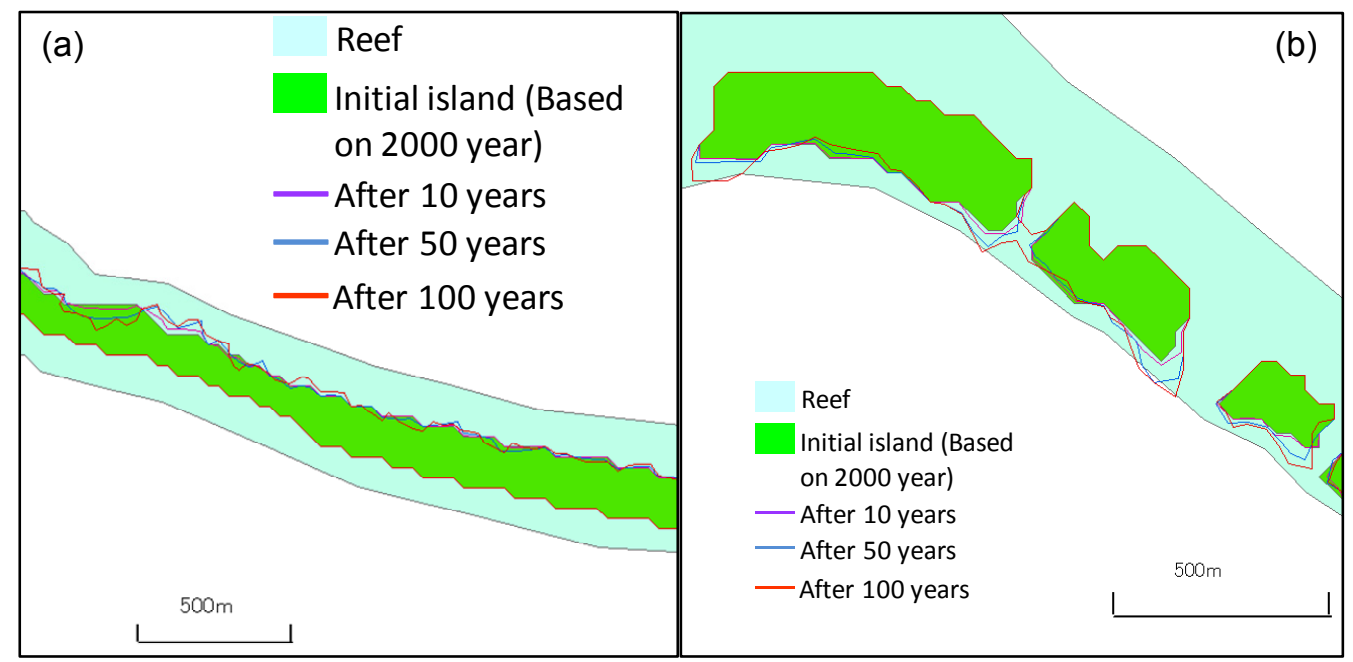

Figure 9. Calculated results of representative shoreline in middle of Laonglsland (a) and small islet of northern part of the atoll (b)

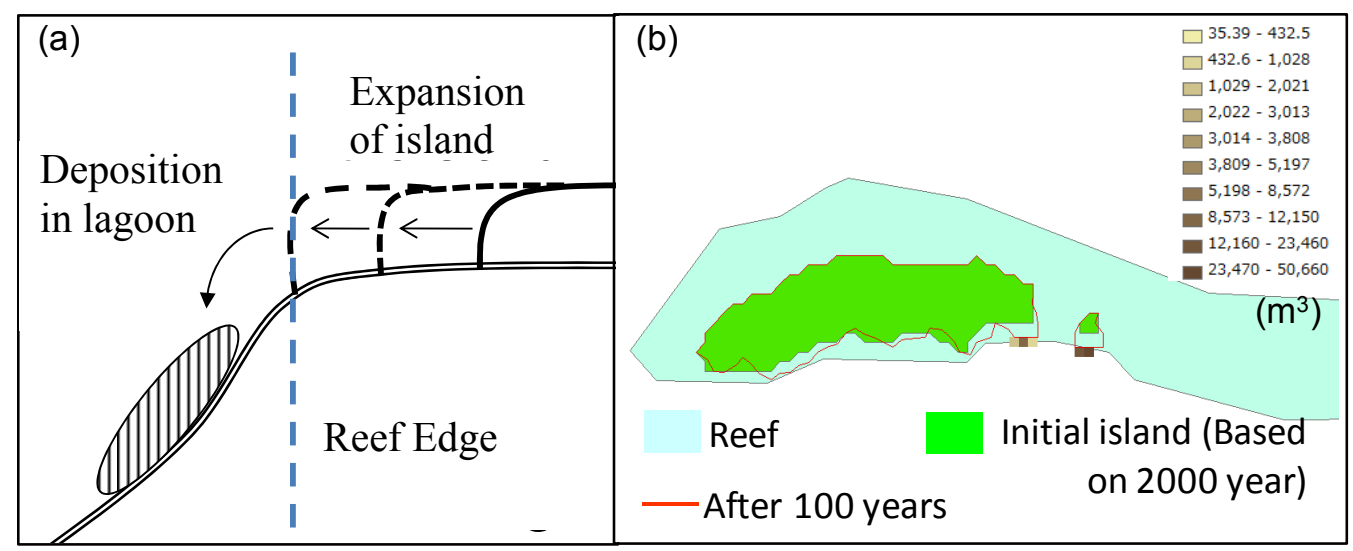

Figure 10. (a) Image of outflow sands, (b) Distribution of outflow sand in northern part of the atoll

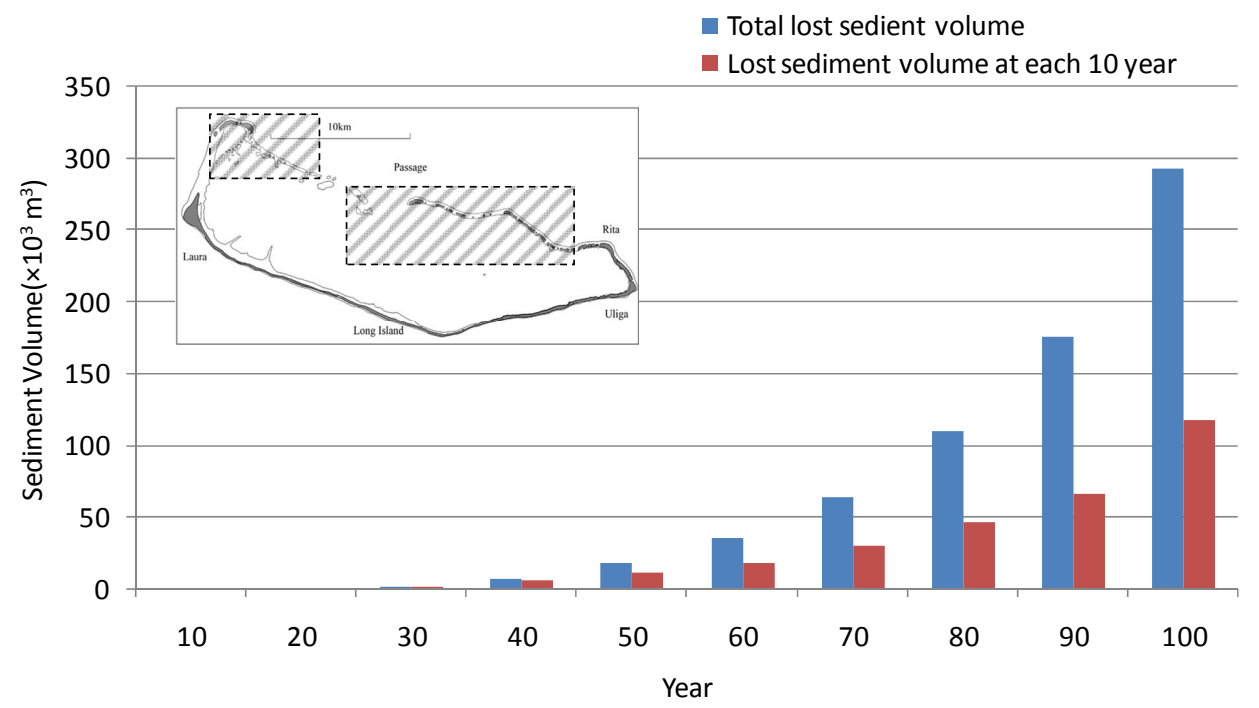

Figure 11. Distribution of outflow sediment volume in northern part of the atoll every 10 years 


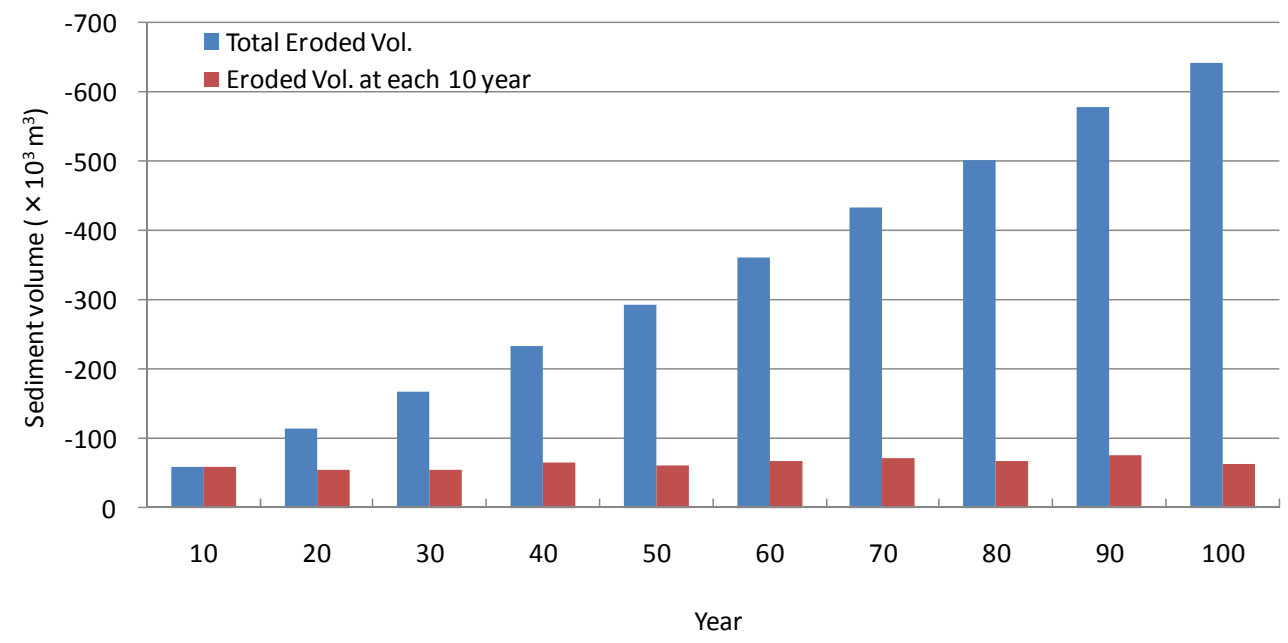

Figure 12. Accumulated ad calculated every 10 years erosion volume

\begin{tabular}{|l|l|l|}
\hline \multicolumn{3}{|c|}{ Table 3. Implementation scenario of beach nourishment } \\
\hline & Trigger & Area \\
\hline NA-1 & shoreline retreat by $1 \mathrm{~m}$ & From Laura to Longlsland \\
\hline NA-2 & shoreline retreat by $5 \mathrm{~m}$ & Same above \\
\hline NA-3 & shoreline retreat by $10 \mathrm{~m}$ & Same above \\
\hline
\end{tabular}

sediment transport system on the reef-flat (Fig. 10 (a)). These outflow sediment volumes were

calculated in many lagoon of northern part of the atoll. Figure 10 (b) shows an example of calculated distribution of the outflow sediment volume. Because of high sediment production in northern atoll, the small islets did not decrease their volume even if the outflow sediment volume was large.

Figure 11 shows the accumulated volume of outflow sediment (blue bar) and volume of outflow sediment every 10 years (red bar). Focused area is also indicated in the figure as diagonal domains. As shown in the figure, the outflow volume does not increase until 40 years later. After 40 years, the outflow sediment volume increase year by year. Increasing rate increased year by year and the accumulated volume of outflow sediment became almost $300 \times 10^{3} \mathrm{~m}^{3} 100$ years later.

Figure 12 shows the accumulated volume of erosion areas in whole of Majuro atoll. Blue bars and red bars indicate the accumulated erosion volume and erosion volume every 10 years respectively. Erosion volumes every 10 years show that the volumes are not increase year by year. It indicated that the net volume of longshore sediment transport was almost same through the simulation time, although the sea-level rise increased neashore wave height and volume of longshore sediment transport. Moreover, it considered that the trend of morphological change was not same though the simulation time. The erosion and accretion area changed due to the effect of morphological changes, which changed the neashore wave situation.

\section{Examination of beach nourishment}

Consideration and examination of island conservation plan are significant for sustainable island use and development in Majuro atoll. Atoll islands have small and limited resource for their development so that the effective and less usage of resources are desirable for conservation plan. Moreover the natural process on sediment transport is should be protected for long-term island conservation. In Majuro atoll, the longshore sediment transports are important process of morphological changes (Xue, 2001; Sato and Yokoki, 2008, 2009). Thus, the conservation plan should not become obstacle of the longshore sediment transportation so that groin and vertical seawall are not desirable. As sustainable and effective conservation, beach nourishment was focused in this study. Sustainable conservation was enabled using the outflow sediment as the source sediment for implementation of beach nourishment. 


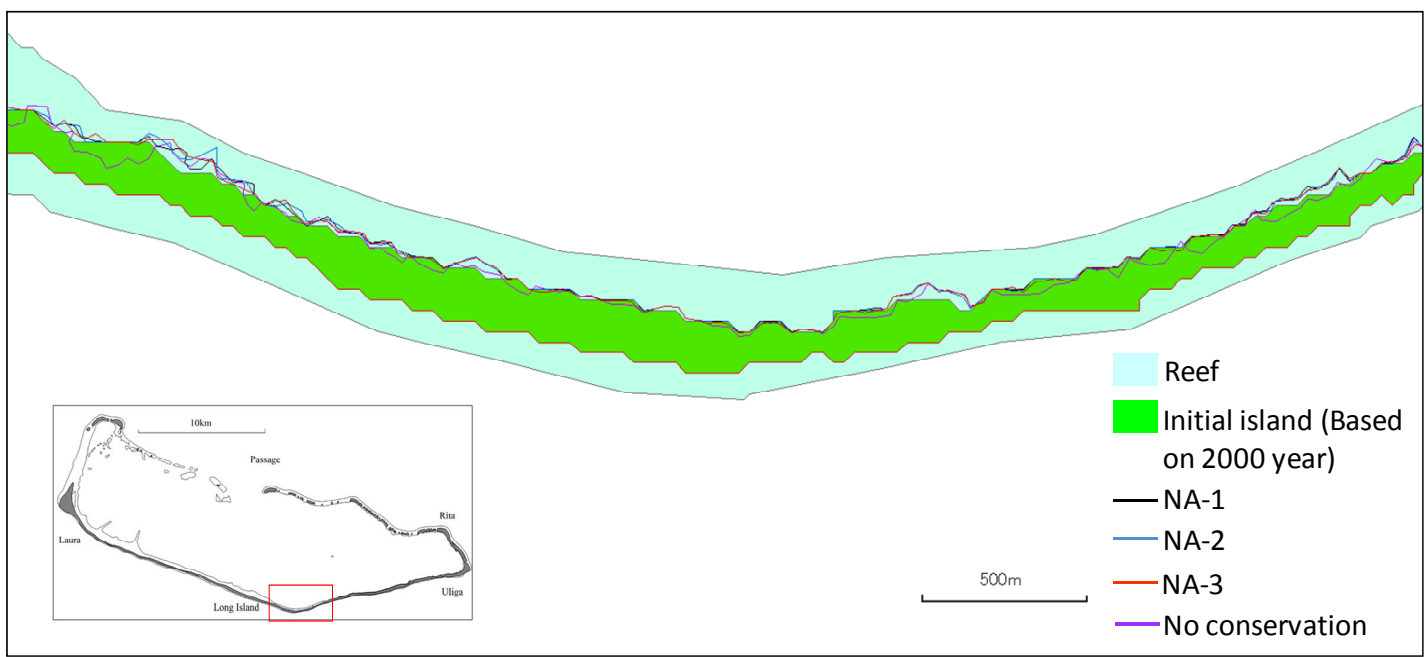

Figure 13. Calculated shoreline position with beach nourishment

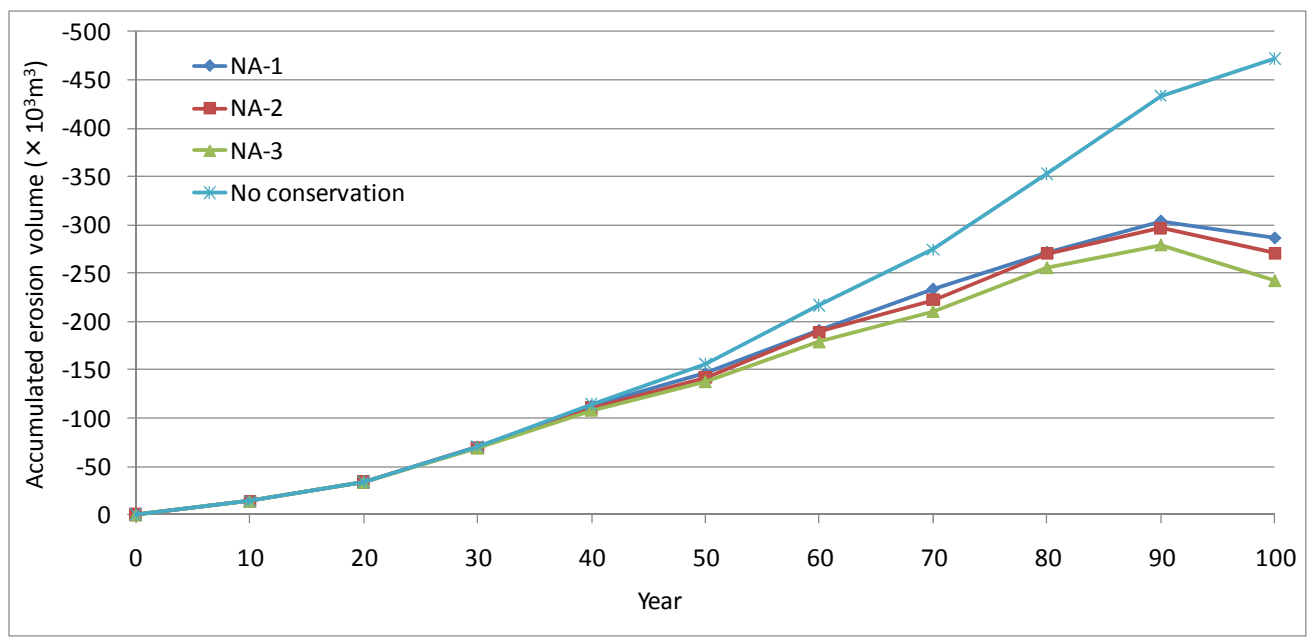

Figure 14. Accumulated erosion volume with and without beach nourishment

Three beach nourishment scenarios were examined in this study (Table 3). Implementation area of all scenarios was set to lagoon-side coast from Laura to LongIsland. DUD located in eastern part of atoll was excepted because it has already vertical seawall. The three scenarios are different in the triggers of implementation that the shoreline retreats by 1,5 and $10 \mathrm{~m}$ respectively. In the simulation, the implementation of the beach nourishment was treated as restoring the initial shoreline position using the outflow sediment volume only. Whether the coast needs to implement the beach nourishment or not was checked every 10 years. If enough sands were not accreted in source area, the beach nourishment was not implemented even if it need in eroded area.

Figure 13 shows an example of calculated results with and without beach nourishment in the middle of LongIsland indicated in the Figure. Calculated shorelines of different scenarios are indicated as the different colored lines. The shoreline without beach nourishment is also described as violet line in Fig. 13. The described shorelines are the calculated result after 100 years. Calculated shoreline with beach nourishment indicated that the beach nourishment banished the large erosion, which was identified from the shoreline position without beach nourishment. Especially the largest erosion in western part of the figure is completely protected. Although there are little differences between scenarios, it is clearly recognized that the beach nourishment was successfully implemented for island conservation after 100 years.

Accumulated erosion volumes every 10 years were identified in Fig. 14. In this figure, three scenarios and one result without beach nourishment are described with colored lines. All lines showed same change until 40 years later because the sediments, which need to implement of beach nourishment, did not accreted in the lagoon of northern part of the atoll. It is indicated that lack of 
accreted sediment unable enough conservation in this study. Beyond 40 years, there was a different between with and without beach nourishment and the different increased year by year. The accumulated erosion volume without conservation increase continuously, which become more than $450 \times 10^{3} \mathrm{~m}^{3}$ after 100 years. Three beach nourishment scenarios (NA-1, 2 and 3) decrease erosion volume behind $300 \times 10^{3} \mathrm{~m}^{3}$. It was indicated that the beach nourishment have effect to decrease the erosion volume about $30 \%$. Although all coasts from Laura to LongIsland was targeted as implementation area in this study, it would be enabled to enhance the effect of beach nourishment by selecting the precedential area for conservation appropriately. Kuwahara et al (2007) analyzed distribution of coastal vegetation and neashore houses using the satellite images and results of field investigation and indicated the precedential area against coastal erosion in Laura islet. In order to enhance and develop more effective conservation plan, the information such as neashore house's distribution and coastal vegetation are would be combined for considering of the detail of sustainable conservation in Majuro atoll.

\section{CONCLUSION}

Future estimation of shoreline changes until 100 years later and examination of beach nourishment using the outflow sediments volume were carried out in this study and the conclusion shows as below.

- This study developed numerical model, which enable to simulate shoreline changes in Majuro atoll. Estimated shoreline position indicated detail of island morphological changes and it was enabled to identify the volumes of erosion and accretion in lagoon-side coasts in Majuro atoll.

- Northern tip of Laura islet and some coasts in LongIsland had severe and continuously erosion until 100 years later. The severe erosion in northern tip of Laura agreed with the information reported by previous studies.

- Small islets located in northern part of the atoll had large accretion in lagoon-side coast. The large accretion connected two separated islands. It seemed that the high sediment production rate and existence of channels caused such large accretion.

- Examination of beach nourishment identified that the accumulated erosion volume was decreased by $30 \%$ of the erosion volume without conservation. Three beach nourishment scenarios examined in this study were sustainable because the sediments of implementation were gathered from outflow sands, which are accreted by natural process in the lagoon. The calculated result showed the possibility and effectiveness of the sustainable beach nourishment using the naturally provided sands in Majuro atoll.

- Selection of precedential area for protection is significant for enhancement of conservation plan proposed in this study. The additional information such as nearshore house's distribution and effect of coastal vegetation should be included to consider the protection area.

\section{ACKNOWLEDGMENTS}

This study was supported by Research Fellowship from the Japan Society for the Promotion of the Science for Young Scientists, partly Global Environment Research Fund (Ba-085), Ministry of the Environment, Japan, and partly MEXT through Special Coordination Funds for Promoting Science and Technology, as a part of the flagship research project for Sustainable measures to mitigate and adapt to global warming undertaken by Ibaraki University. The authors considerably appreciate them.

\section{REFERENCES}

Baines, G.B.K., and R.F. McLean. 1976. Sequential studies of hurricane deposit evolution at Funafuti Atoll. Marine Geology, 21, M1-M7.

Booij, N.R., C. Ris, and L.H. Holthuijsen. 1999. A third-generation wave model for coastal regions 1. Model description and validation , Journal of Geophysical Research, Vol.104 , No.C4 , 76497666.

Coastal Engineering Research Center (CERC). 1984. Shore Protection Manual.

Fujita, K., Y. Osawa, H. Kayanne, Y. Ide, and H. Yamano. 2009. Distribution and sediment production of large benthic foraminifers on reef flats of the Majuro Atoll, Marshall Islands, Coral Reefs, 28, $29-45$. 
Kayanne, H., M. Chikamori, H. Yamano, T. Yamaguchi, H. Yokoki, and H. Shimazaki. 2005. Interdisciplinary Approach for Sustainable Land Management of Atoll Islands, Global Environmental Research, 9(1), 1-7.

Kench, P.S., and R.W. Brander. 2006. Wave processes on coral reef flats: Implications for reef geomorphology using Australian case studies, Journal of Coastal Research, 22, 1, 209-223.

Komar, P.D., and D.L. Inman. 1970. Longshore sand transport on beaches, Journal of Geophysical Research, 30, 5914-5927.

Kuwahara, Y., H. Yokoki, D. Sato, and N. Mimura. 2007. Coastal Zoning Process for Land Protection on Majuro Atoll, Journal of Applied Computing in Civil Engineering, Vol.16, 91-98. (In Japanese)

Leatherman, S.P. 1977. Sea-level rise and small island states: An overview, Journal of Coastal Research, Special Issue 24, 1-16.

Maragos, J.E., G.B.K. Baines, and P.J. Beveridge. 1973. Tropical cyclone creates a new land formation on Funafuti atoll. Science, 181, 1161-1164.

Mergner, H. 1985. Initial recolonization of Funafuti Atoll coral reefs devastated by hurricane "Bebe", Atoll Research Bulletin, No.284, 1-16.

Mimura, N., L. Nurse, R.F. McLean, J. Agard, L. Briguglio, P. Lefale, R. Payet, and G. Sem. 2007. Small islands. Climate Change 2007: Impacts, Adaptation and Vulnerability. Contribution of Working Group II to the Fourth Assessment Report of the Intergovernmental Panel on Climate Change, M.L. Parry, O.F. Canziani, J.P. Palutikof, P.J. van der Linden and C.E. Hanson, Eds., Cambridge University Press, Cambridge, UK, 687-716.

Nurse, L.A., G. Sem, J.E. Hay, A.G. Suarez, P.P. Wong, L. Brigulio, and S. Ragoonaden. 2001. Small Island states. In: J.J. McCarthy, O.F. Canziani, N.A. Leary, D.J. Dokken and K.S. White, eds., Climate Change 2001: Impacts, Adaptation, and Vulnerability. Contribution of Working Group II to the Third Assessment Report of the Intergovernmental Panel on Climate Change, Cambridge University Press, Cambridge, 843-875.

Sato, D., H. Yokoki, K. Fujita, Y. Kuwahara, H. Yamano, H. Shimazaki, H. Kayanne, and M. Watanabe. 2006. Numerical Calculation of the Topographical Maintenance Process Change due to Sea-Level Rise in Majuro Atoll, the Marshall Islands, Annual Journal of Coastal Engineering, JSCE, Vol. 53, (2),1291-1295. (In Japanese)

Sato, D., and H. Yokoki. 2008. Field investigation and numerical simulation toward the control of longshore sediment transport on Laura islet in Majuro Atoll, Annual Journal of Coastal Engineering, JSCE, Vol. 55, (2), 1401-1405. (In Japanese)

Sato, D., and H. Yokoki. 2009. Numerical calculation of the sediment transports along the lagoonal coast on Majuro Atoll, Proceedings of Coastal Dynamics 2009, No.95, 1-11.

SOPAC. 1997. Beach monitoring in Dud and Laura, Majuro Atoll, Republic of the Marshall Islands, SOPAC Preliminary Report, No. 88, ANNEX 2 Beach Profile Data.

SOPAC. 1998. Re-survey of Dud and Laura beach profiles Majuro Atoll, Republic of the Marshall Islands, SOPAC Preliminary Report, No. 93, APPENDIX 1 Beach Profile Data.

Xue, C. 1997. Coastal Sedimentation Erosion and Management of Majuro Atoll Republic of Marshall Islands, SOPAC Technical Report, 254, 1-80.

Xue, C. 2001. Coastal erosion and management of Majuro Atoll, Marshall Islands, Journal of Coastal Research, 17(4), 909-918.

Yamano, H., H. Kayanne, and M. Chikamori. 2005. An Overview of The Nature and Dynamics of Reef Islands, Global Environmental Research, 9(1), 9-20.

Yasukouchi, T. 2007. Ecological and phisical factors of Holocene atoll-island formation in the Pacific, Ph. D Thesis of University of Tokyo, 1-129.

Yokoki, H., H. o, H. Kayanne, D. Sato, Y. Minami, S. Ando, H. Shimazaki, T. Yamaguchi, M. Chikamori, A. Ishoda, and H. Takagi. 2005. Comparison between Longshore Sediment Transport Due to Waves and Long-term Shoreline Change in Majuro Atoll, Marshall Islands, Global Environmental Research, 9(1), 21-26. 